\title{
Effect of siRNA silencing of inducible co-stimulatory molecule on myocardial cell hypertrophy after cardiac infarction in rats
}

\author{
W.M. Wang, Z. Liu and G. Chen \\ Department of Interventional Medicine, Binzhou Medical College Hospital, \\ Binzhou, China \\ Corresponding author: W.M. Wang \\ E-mail: wenmingwang168@163.com
}

Genet. Mol. Res. 15 (2): gmr.15027338

Received September 14, 2015

Accepted December 15, 2015

Published May 20, 2016

DOI http://dx.doi.org/10.4238/gmr.15027338

\begin{abstract}
As the most common cardiac disease, myocardial infarction is followed by hypertrophy of cardiac myocytes and reconstruction of ventricular structure. The up-regulation of a series of factors including metalloproteinases, inflammatory factors, and growth factors after primary infarction lead to the hypertrophy, apoptosis, necrosis, and fibroblast proliferation in cardiac muscle tissues. Recent studies have reported on the potency of small interfering RNA (siRNA) in treating cardiac diseases. We thus investigated the efficacy of inducible co-stimulatory molecule (ICOS)-specific siRNA silencing in myocardial hypertrophy in a cardiac infarction rat model. This cardiac infarction model was prepared by ligating the left anterior descending coronary artery. ICOS-siRNA treatment was administered in parallel with non-sense siRNA. After 18 days, the cross-sectional area of cardiac muscle tissues and the left ventricle weight index were measured, along with ICOS mRNA and protein expression levels, and pathological staining. Compared to those in the control groups, in myocardial infarcted rats, the application of ICOS-siRNA effectively decreased the left ventricle weight index, as well as the surface area of
\end{abstract}


cardiac myocytes. Both mRNA and protein levels of ICOS were also significantly decreased. HE staining was consistent with these results. In conclusion, ICOS-targeted siRNA can effectively silence gene expression of ICOS, and provided satisfactory treatment efficacy for myocardial cell hypertrophy after infarction.

Key words: Inducible co-stimulatory molecule; RNA interference; Myocardial infarction; Myocardial cell hypertrophy

\section{INTRODUCTION}

The major morphological change after myocardial infarction is myocardial cell hypertrophy. Various studies have confirmed this progressive compensatory response in cardiovascular diseases, which is due to stimulation by various pathological factors, and ultimately leads to elevated cardiac loads. The hypertrophy of myocardial cells can lead to certain compensatory functions at its early stages (McMurray and Pfeffer, 2005; Morishita et al., 2015). However, with disease progression, hypertrophy eventually leads to heart failure and death. Previous studies have revealed that the Rho GTP kinase family participates in signal transduction during reformation events in myocardial hypertrophy and in heart failure. Moreover, ventricular reconstruction after primary myocardial infarction can cause myocardial injury, and can lead to secondary alternations to myocardial molecules and to the intracellular matrix. The elevation of inflammatory factors, matrix metalloproteinase, and growth factors can all lead to the necrosis/apoptosis of myocardial cells and to the proliferation of fibroblasts. Further changes to the intracellular matrix can cause the degradation and fibrosis of the extracellular matrix in addition to ventricle reconstruction. Reports have revealed that the mortality rate of acute myocardial infarction has fallen to approximately $0.02 \%$ due to the advancement of medical technologies, especially those in interventional therapies in cardiovascular diseases (McMurray and Pfeffer, 2005). However, the mortality rate caused by secondary hypertrophic changed in myocardial cells has continued to increase in recent years, making interventions for myocardial cell hypertrophy a focus of recent research. Despite this, current studies have only been concerned with the research of molecular/cellular biology features of the cardiovascular system regulated by the neurohumor.

Inducible costimulatory molecule (ICOS) is now considered an important factor crucial for T cell induction. ICOS is mainly expressed in active T cells, which show elevated ICOS expression $6 \mathrm{~h}$ after activation while reaching a peak at $12 \mathrm{~h}$. Other than T cells, ICOS is also expressed at moderate levels in normal tissues (Hutloff et al., 1999). However, the pathophysiological role of ICOS in hearts remains unclear. Therefore, we investigated ICOS mRNA and protein expression levels via RNA-interfering methods in an attempt to elucidate the effects of ICOS expression on myocardial cell hypertrophy.

\section{MATERIAL AND METHODS}

\section{Myocardial infarction animal model}

A total of 30 male Wistar rats (body weight: $185 \pm 11 \mathrm{~g}$ ) were provided by the Animal Research Center of Binzhou Medical College. After anesthesia, the chest cavity was open to 
expose the coronary artery, of which the left descending branch was ligated to generate the myocardial infarction model. Animals with successful infarction were randomly divided into the myocardial infarction (M1) group, non-sense siRNA transfected group, and ICOS-siRNA group ( $\mathrm{N}=10$ per group). The M1 group received no treatment. In the ICOS siRNA group, siRNA (dissolved in $0.1 \mathrm{~mL}$ PBS) was injected into the anterior wall of hearts every other day. The non-sense siRNA group received the same injection procedure using PBS instead. Rats were used for all experiments, and all procedures were approved by the Animal Ethics Committee of Binzhou Medical College Hospital.

\section{Sample collection and pathological staining}

Eighteen days after generating infarction rats, the animals were euthanized to extract left ventricle samples inside the brain. The non-infarcted area of the left ventricle was further sectioned (2-3 mm thickness) and fixed in 10\% formalin. After paraffin embedding and sectioning, hematoxylin and eosin (H\&E) staining was used to reveal pathological changes as previously described (Hutloff et al., 1999). The cross sectional area of 100 myocardial cells in 9-10 fields was measured and averaged.

\section{RT-PCR}

Total RNA were extracted from ventricular tissue samples using a KPL RNA extraction kit (Kirkegaard \& Perry Laboratories, Inc., Gaithersburg, MD, USA) following the manufacturer instructions. First-strand cDNAs were synthesized in 20 re volume using 1 $\mathrm{d}$ in 20 with the Bio-Rad iScript cDNA synthesis kit. Real-time quantitative PCR was then performed with specific primers (ICOS-forward, 5'-GUG CAC GAC UCA AUA TA-3'; ICOSreverse, 5'-TTC ACG UGC UGA CFC AG-3') by applying iQ SYBR Green Supermix (BioRad, Hercules, CA, USA). Amplification conditions were as follows: pre-denature for $2 \mathrm{~min}$ at $94^{\circ} \mathrm{C} ; 40$ cycles of denaturing for $5 \mathrm{~s}$ at $94^{\circ} \mathrm{C}$, annealing for $30 \mathrm{~s}$ at $60^{\circ} \mathrm{C}$, and elongation for $15 \mathrm{~s}$ at $72^{\circ} \mathrm{C}$. Relative mRNA expression levels were determined using the $2^{-\Delta \Delta \mathrm{Ct}}$ method with GAPDH (forward, 5'-CCC ACT AAC ATC AAA TGG GG-3'; reverse, 5'-CCT TCC ACA CAA AGT T-3') serving as an internal control.

\section{Western blotting}

Left ventricular tissue samples $(100 \mathrm{mg})$ were collected for total protein extraction. Proteins were separated via SDS-PAGE (5\% acrylamide, $40 \mathrm{~V}, 1 \mathrm{~h}$, and $60 \mathrm{~V}, 3.5 \mathrm{~h}$ ) and transferred to PVDF membranes. After blocking at $37^{\circ} \mathrm{C}$ for $2 \mathrm{~h}$, a rabbit anti-mouse antibody against ICOS (1:1000, Santa Cruz Biotechnology, Santa Cruz, CA, USA) was applied to the membranes, which were then incubated for $2 \mathrm{~h}$ at $37^{\circ} \mathrm{C}$. The membranes were then rinsed with TBST, and incubated with a goat anti-rabbit IgG antibody (1:1500, Santa Cruz Biotechnology) for another $1.5 \mathrm{~h}$ at $37^{\circ} \mathrm{C}$. ECL reagent (KPL) was added to develop the membranes. Using beta-actin as the internal reference, the relative optical density of all protein bands was measured to determine relative protein levels.

\section{Statistical analysis}

All data are presented as the mean \pm standard deviation. The SPSS 15.0 software 
(SPSS Inc., Chicago, IL, USA) was used to compare the means between two groups by the Student $t$-tests. Analysis of variance (ANOVA) and q-tests were used for multiple group comparisons. Statistical significance was defined as $\mathrm{P}<0.05$.

\section{RESULTS}

\section{Morphological features of myocardial tissues}

We used H\&E staining to examine the tissue morphology of the left ventricle non-infarcted regions from the different treatment groups. Results showed that there was myocardial cell hypertrophy with dispersed hemorrhage lesions in the control and non-sense siRNA groups (Figure 1). The ICOS-siRNA group, however, had no significant myocardial cells hypertrophy.
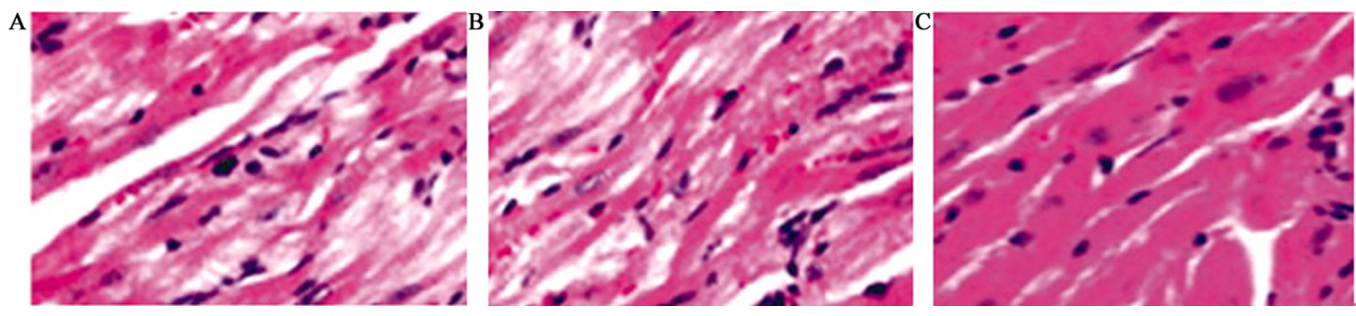

Figure 1. Tissue morphology of myocardial cells. A. Control group; B. non-sense siRNA treatment group; C. ICOS-siRNA treatment group. Magnification $=200 \mathrm{X}$.

\section{Index of myocardial cell hypertrophy}

The evaluation of myocardial hypertrophy was based on the left ventricular weight index (normalized against body weight as LVW/BW) and the cross sectional area of 100 myocardial cells. We found that these hypertrophy indices in ICOS-siRNA treated rats were significantly decreased compared to those in the control and non-sense siRNA groups $(\mathrm{P}<$ 0.05 , Table 1).

Table 1. Myocardial hypertrophy index.

\begin{tabular}{l|c|c|c}
\hline Group & MI group & Non-sense siRNA & ICOS siRNA \\
\hline Cross section area of myocardial cells $\left(\mu \mathrm{m}^{2}\right)$ & $2,075,867 \pm 175,489$ & $2,120,345 \pm 181,934$ & $1,397,563 \pm 93,653$ \\
\hline LVW/BW $(\mathrm{mg} / \mathrm{g})$ & $2.30 \pm 0.17$ & $2.29 \pm 0.16$ & $1.81 \pm 0.12$ \\
\hline
\end{tabular}

\section{ICOS mRNA expression}

After 18 days of siRNA or control treatments, the mRNA levels of ICOS were markedly decreased in the ICOS-siRNA treated group compared to those in either the control (MI) or non-sense siRNA groups $(\mathrm{P}<0.05$, Figure 2$)$. 


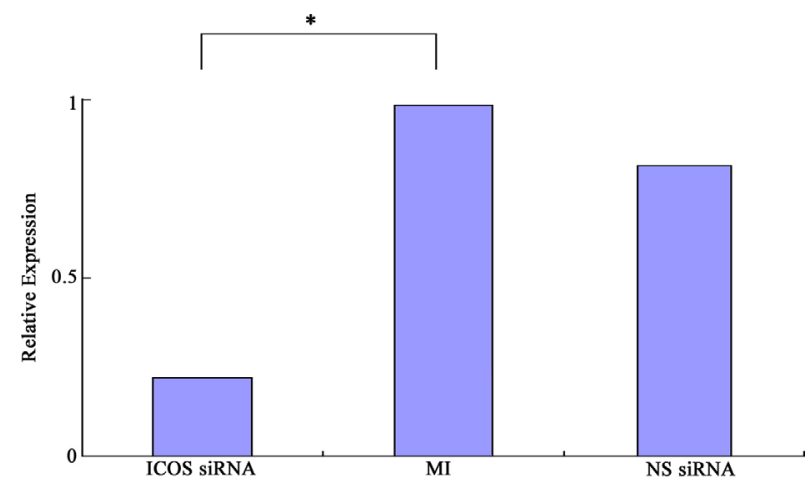

Figure 2. ICOS mRNA level by RT-PCR. *P $<0.05$ compared to MI group.

\section{ICOS protein levels}

We obtained consistent results when examining the protein expression levels of ICOS via western blot, of which the expression was significantly decreased in the ICOS-siRNA group compared to those of the two control groups $(\mathrm{P}<0.05$, Figure 3$)$.
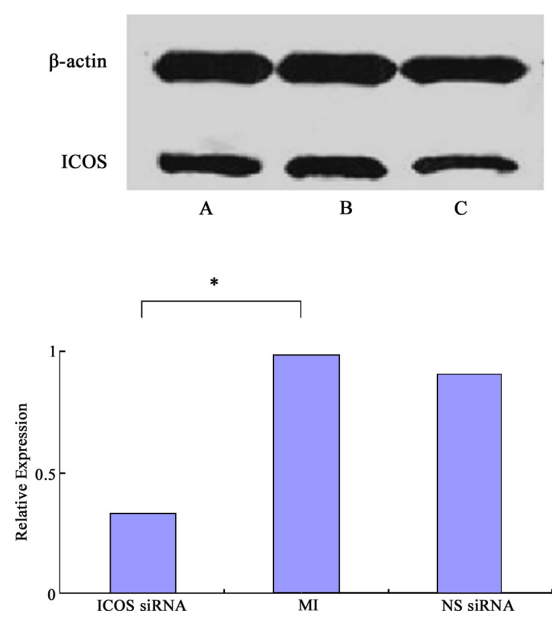

Figure 3. ICOS protein level. Upper panel shows representative blotting bands. A. non-sense siRNA group; B. MI group; C. ICOS-siRNA group. Lower panel shows quantitative data of ICOS protein expression levels. ${ }^{*} \mathrm{P}<0.05$ compared to MI group.

\section{DISCUSSION}

Secondary myocardial dysfunction following initial cardiac infarction can lead to heart failure and death. Recent advancements such as those in intervention therapies have remarkably decreased the mortality of heart diseases (Nozato et al., 2000; Galla \& Whitlow, 2010; Melikian et al., 2010; Barbou et al., 2013). However, myocardial hypertrophy continues to manifest in clinics, which can aggravate heart failure and cause malignant cardiac arrhythmia, creating a need to elucidate the molecular mechanisms underlying myocardial cell hypertrophy 
(Sah et al., 1999; Wu et al., 2001; Ardehali et al., 2012; Grundeken et al., 2014). Apoptosis of myocardial cells forms the cellular basis of the transition of heart disease from compensatory alternation to pathological changes, thus playing a crucial role in the development of cardiac disease. The typical feature of apoptotic cells are the shrinking of the cell body, lysis of the nucleus, and dense chromatin, followed by membrane budding and apoptotic bodies, which are eventually digested by macrophages. Bax-related inflammatory factors, mitochondria, and the sarcoplasmic reticulum are all involved in this process (Hutloff et al., 1999; Nozato et al., 2000; Galla and Whitlow, 2010; Melikian et al., 2010). During ventricular reconstruction, apoptotic cells have been found in both infarcted and non-infarcted regions of myocardial tissues, leading to decreased numbers of functional myocardial cells. Animal experiments have found that the number of apoptotic cells in myocardial tissues reaches a peak only $2 \mathrm{~h}$ after coronary artery ligation in rats, which is followed by significant decreases in cell numbers and severely impaired cardiac functions (Ardehali et al., 2012; Barbou et al., 2013). A series of pathological processes follow the occurrence of myocardial infarction. Although beta-receptor antagonists can improve the prognosis of myocardial infarction patients, the incidence of secondary cardiac dysfunction has continued to increase in recent years, severely affecting the overall survival rate. Therefore, recent research has focused on the mechanisms of and treatments against myocardial cell hypertrophy. Current therapeutic studies in this field have mainly focused on stem cell transplantation for myocardial cell regeneration, and modulation of autonomic nerve homeostasis in both animal models and preliminary clinical trials. However, further studies are required to elucidate the potential mechanisms involved in myocardial hypertrophy.

As one important tool for genetic research, RNAi can specifically inhibit target gene expression by base pairing, with advantages that include delivery of small molecules, high specificity, and inheritance. Moreover, siRNA is currently being used in the field of gene therapy (Galla and Whitlow, 2010).

In this study, we first generated a rat model of myocardial infarction, which accurately recapitulated the heart failure of patients that is secondary to myocardial infarction. We then utilized siRNA methods to specifically down-regulate ICOS gene expression (Hasenfuss, 1998; Piao et al., 2010; Georgiopoulou et al., 2013; Kazi and Mark, 2013; Mandel and Poch, 2013). The small molecule siRNA can specifically induce the degradation of target genes under certain circumstances, leading to the down-regulation of target genes and related biological functions, all of which may be associated with the occurrence of myocardial hypertrophy (Hunt et al., 2001; Yanazume et al., 2002; Mita et al., 2005; Rosamond et al., 2008). Our results showed that after 18 days of ICOS gene silencing, the surface area of myocardial cells, left ventricular weight index, and ICOS expression levels were significantly decreased in the ICOS-siRNA treatment group compared those in the control (MI) or non-sense siRNA groups. Pathological examinations revealed no significant hypertrophy of myocardial tissues after ICOS-siRNA treatment. In summary, our study demonstrates the effect of ICOS gene expression, activity, and related functions on myocardial hypertrophy secondary to cardiac infarction. Importantly, the silencing of ICOS may inhibit the occurrence of myocardial hypertrophy. This study provides evidence and guidance for further investigations of clinical interventions for secondary myocardial hypertrophy.

\section{Conflicts of interest}

The authors declare no conflict of interest. 


\title{
ACKNOWLEDGMENTS
}

\author{
Research supported by the Natural Science Foundation of Shandong Province \\ (\#ZR2010HM091).
}

\section{REFERENCES}

Ardehali H, Sabbah HN, Burke MA, Sarma S, et al. (2012). Targeting myocardial substrate metabolism in heart failure: potential for new therapies. Eur. J. Heart Fail. 14: 120-129. http://dx.doi.org/10.1093/eurjhf/hfr173

Barbou F, Schiano P and Lahutte M (2013). Intramyocardial haemorrhage and microvascular obstruction after primary percutaneous coronary intervention. Arch. Cardiovasc. Dis. 106: 66-68.http://dx.doi.org/10.1016/j.acvd.2011.09.005

Galla JM and Whitlow PL (2010). Coronary chronic total occlusion. Cardiol. Clin. 28: 71-79. http://dx.doi.org/10.1016/j. ccl.2009.10.003

Georgiopoulou VV, Kalogeropoulos AP, Borlaug BA, Gheorghiade M, et al. (2013). Left ventricular dysfunction with pulmonary hypertension: Part 1: epidemiology, pathophysiology, and definitions. Circ Heart Fail 6: 344-354. http:// dx.doi.org/10.1161/CIRCHEARTFAILURE.112.000095

Grundeken MJ, Kraak RP, Baan J, Jr., Arkenbout EK, et al. (2014). First report on long-term clinical results after treatment of coronary bifurcation lesions with the Tryton dedicated bifurcation stent. Catheter. Cardiovasc. Interv. 84: 759765. http://dx.doi.org/10.1002/ccd.25350

Hasenfuss G (1998). Animal models of human cardiovascular disease, heart failure and hypertrophy. Cardiovasc. Res. 39: 60-76. http://dx.doi.org/10.1016/S0008-6363(98)00110-2

Hunt SA, Baker DW, Chin MH, Cinquegrani MP, et al.; American College of Cardiology/American Heart Association Task Force on Practice Guidelines (Committee to Revise the 1995 Guidelines for the Evaluation and Management of Heart Failure); International Society for Heart and Lung Transplantation; Heart Failure Society of America (2001). ACC/AHA Guidelines for the Evaluation and Management of Chronic Heart Failure in the Adult: Executive Summary A Report of the American College of Cardiology/American Heart Association Task Force on Practice Guidelines (Committee to Revise the 1995 Guidelines for the Evaluation and Management of Heart Failure): Developed in Collaboration With the International Society for Heart and Lung Transplantation; Endorsed by the Heart Failure Society of America. Circulation 104: 2996-3007.http://dx.doi.org/10.1161/hc4901.102568

Hutloff A, Dittrich AM, Beier KC, Eljaschewitsch B, et al. (1999). ICOS is an inducible T-cell co-stimulator structurally and functionally related to CD28. Nature 397: 263-266. http://dx.doi.org/10.1038/16717

Kazi DS and Mark DB (2013). The economics of heart failure. Heart Fail. Clin. 9: 93-106. http://dx.doi.org/10.1016/j. hfc. 2012.09 .005

Mandel J and Poch D (2013). In the clinic. Pulmonary hypertension. Ann. Intern. Med. 158: Itc5-1-16.

McMurray JJ and Pfeffer MA (2005). Heart failure. Lancet 365: 1877-1889. http://dx.doi.org/10.1016/S01406736(05)66621-4

Melikian N, Del Furia F and Di Mario C (2010). Physiologic lesion assessment during percutaneous coronary intervention. Cardiol. Clin. 28: 31-54.http://dx.doi.org/10.1016/j.ccl.2009.10.002

Mita S, Kobayashi N, Yoshida K, Nakano S, et al. (2005). Cardioprotective mechanisms of Rho-kinase inhibition associated with eNOS and oxidative stress-LOX-1 pathway in Dahl salt-sensitive hypertensive rats. J. Hypertens. 23: 87-96. http://dx.doi.org/10.1097/00004872-200501000-00017

Morishita K, Takemura G, Tsujimoto A, Kanamori H, et al. (2015). Postinfarction Cardiac Remodeling Proceeds Normally in Granulocyte Colony-Stimulating Factor Knockout Mice. Am. J. Pathol. 185: 1899-1911. http://dx.doi. org/10.1016/j.ajpath.2015.03.018

Nozato T, Ito H, Tamamori M, Adachi S, et al. (2000). G1 cyclins are involved in the mechanism of cardiac myocyte hypertrophy induced by angiotensin II. Jpn. Circ. J. 64: 595-601. http://dx.doi.org/10.1253/jci.64.595

Piao L, Marsboom G and Archer SL (2010). Mitochondrial metabolic adaptation in right ventricular hypertrophy and failure. J. Mol. Med. 88: 1011-1020. http://dx.doi.org/10.1007/s00109-010-0679-1

Rosamond W, Flegal K, Furie K, Go A, et al.; American Heart Association Statistics Committee and Stroke Statistics Subcommittee (2008). Heart disease and stroke statistics--2008 update: a report from the American Heart Association Statistics Committee and Stroke Statistics Subcommittee. Circulation 117: e25-e146. http://dx.doi.org/10.1161/ CIRCULATIONAHA.107.187998

Sah VP, Minamisawa S, Tam SP, Wu TH, et al. (1999). Cardiac-specific overexpression of RhoA results in sinus and atrioventricular nodal dysfunction and contractile failure. J. Clin. Invest. 103: 1627-1634.http://dx.doi.org/10.1172/ $\underline{\mathrm{JCI} 6842}$ 
Wu G, Yussman MG, Barrett TJ, Hahn HS, et al. (2001). Increased myocardial Rab GTPase expression: a consequence and cause of cardiomyopathy. Circ. Res. 89: 1130-1137. http://dx.doi.org/10.1161/hh2401.100427

Yanazume T, Hasegawa K, Wada H, Morimoto T, et al. (2002). Rho/ROCK pathway contributes to the activation of extracellular signal-regulated kinase/GATA-4 during myocardial cell hypertrophy. J. Biol. Chem. 277: 8618-8625. http://dx.doi.org/10.1074/jbc.M107924200 